\title{
La convergencia mediática, los riesgos y el daño online que encuentran los menores
}

\section{Media convergence, risk and harm to children online}
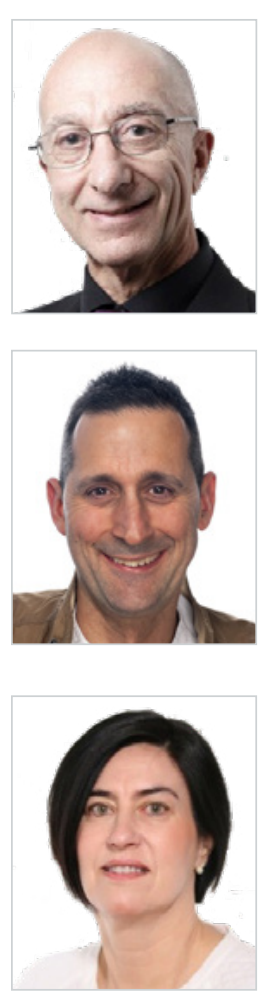

Carmelo Garitaonandia. Catedrático de la Universidad del País Vasco, (UPV/EHU) y ha sido vicerrector de dicha Universidad de 2009 a 2017. Doctor en Ciencias Políticas, licenciado en Derecho y Máster en Comunicación Audiovisual por la Universidad de París VII. Ha escrito numerosos artículos científicos y libros sobre la historia de la comunicación, la TV regional y la TV digital. En las dos últimas décadas ha centrado su investigación en las tecnologías de la información y la comunicación y su influencia en la infancia y en la juventud. Es miembro, desde 2006, del grupo internacional EU Kids Online y tiene cinco sexenios de investigación (CNEAI).

Universidad del País Vasco

carmelo.garitaonandia@ehu.eus

ORCID: 0000-0003-1662-4566

Inaki Karrera. Profesor Agregado de Pedagogía en la Facultad de Educación, Filosofía y Antropología (UPV/EHU) en Donostia-San Sebastián. Este investigador ha tomado parte en proyectos de investigación europeos (Socrates-Grundtvig 2010-1-FR1-GRU06-00253-1), estatales (en varias ocasiones), además de otras investigaciones a nivel de universidad o autonómico donde ha sido o es el investigador principal (IP) o investigador colaborador. Sus líneas de investigación giran en torno a temáticas relacionadas con la Inclusión Educativa, Inclusión digital, desigualdades sociales e Innovación Pedagógica. El profesor Karrera cuenta con un sexenio de investigación (CNEAI). Universidad del País Vasco

inaki.karrera@ehu.eus

ORCID: 0000-0003-4448-7749

Nekane Larrañaga. Profesora Agregada de Sociología en la Facultad de Educación, Filosofía y Antropología de la Universidad del País Vasco UPV/EHU, Donostia-San Sebastián. Ha participado como investigadora en varios proyectos de investigación competitivos a nivel autonómico y otros proyectos a nivel de universidad, en este caso como investigadora principal (IP). Cuenta con un sexenio de investigación (CNEAI) y ha codirigido una tesis doctoral. Los temas sobre los que ha centrado su trabajo de investigación son: diversidad, relaciones interculturales e interétnicas, educación, valores y escuela, bilingüismo, identidad, ciudadanía o aculturación.

Universidad del País Vasco

nekane.larranaga@ehu.eus

ORCID: 0000-0002-8062-3544
Cómo citar este artículo:

Garitaonandia, C.; Karrera, I.; Larrañaga, N. (2019). La convergencia mediática, los riesgos y el daño online que encuentran los menores. Doxa Comunicación, 28, pp. 179-200. 
Recibido: 16/11/2018 - Aceptado: 08/03/2019

\section{Resumen:}

Los medios móviles (smatphones y tabletas) les permiten a los menores tener unos hábitos más flexibles y personalizados, y crear nuevas oportunidades de uso privado dentro del hogar, la escuela y el espacio público. El proyecto Net Children Go Mobile ${ }^{l}$, en el que han participado Dinamarca, Italia, Reino Unido, Rumanía, Bélgica, Irlanda, Portugal y España, se basa en el análisis de esta nueva realidad y de sus posibles consecuencias para la infancia. Este estudio presenta los resultados más significativos de este proyecto en España a partir de la encuesta realizada a 500 menores españoles usuarios y usuarias de internet de entre 9 y 16 años y a su padre o a su madre. Uno de los mayores hallazgos de este proyecto es que las experiencias de riesgo online no conducen necesariamente al daño, tal y como indicaron los propios menores. De hecho, la investigación EU Kids Online mostró que los niños y las niñas que se encuentran con mayor número de riesgos online no son necesariamente quienes sufren consecuencias más dañinas por el contrario, normalmente son ellos quienes demuestran más habilidades y desarrollan más resiliencia.

\section{Palabras clave:}

Internet, menores, riesgos, daño, ciberacoso, sexting.
Received: 16/11/2018 - Accepted: 08/03/2019

\section{Abstract:}

Mobile media such as smartphones and tablets allow children to have more flexible and personalized habits, and create new opportunities for private use within the home, school and public spaces. The project known as Net Children Go Mobile, in which Denmark, Italy, United Kingdom, Romania, Belgium, Ireland, Portugal and Spain have participated, is focused on the analysis of this new reality and its possible consequences for children. This study presents the most significant results of this project in Spain, based on a survey of 500 Spanish children between the ages of 9 and 16, and either their father or their mother. One of the major findings is that online risk does not necessarily lead to harm, as indicated by the children themselves. In fact, the research project entitled EU Kids Online showed that children who face the highest number of online risks are not necessarily the ones who suffer the most harmful consequences; on the contrary, they are usually the ones who have greater skills and develop more resilience.

\section{Keywords:}

Internet, children, risks, harm, cyberbullying, sexting.

\section{Introducción}

Los menores están creciendo en un sistema de convergencia mediática (Ito et al., 2009) que les proporciona oportunidades para la socialización, la auto-expresión, el aprendizaje, la creatividad y la participación a través de los medios online y, crecientemente, los medios móviles (Hjorth \& Goggin, 2009; Goggin, 2010; Goggin \& Hjorth, 2014). Sin embargo, además de las oportunidades que ofrece Internet, los niños y las niñas también experimentan riesgos evidenciando la interdependencia de ambos (Livingstone, Haddon, Görzig \& Ólafsson, 2011): cuanto más usan los menores internet, mayor es la gama de oportunidades que tienen y mayor es la exposición a experiencias de riesgo.

Los medios móviles (smartphones y tabletas) les permiten a los menores tener unos hábitos más flexibles y personalizados, y crear nuevas oportunidades de uso privado dentro del hogar, la escuela y el espacio público. El proyecto Net Children Go Mobile $^{2}$ se basa en el análisis de esta nueva realidad y de sus posibles consecuencias para la infancia y sus familias.

Durante la pasada década, el número de investigaciones sobre riesgos para menores en internet ha sido considerable (Ólafsson, Livingstone \& Haddon, 2013). Sin embargo, la mayoría de los estudios se han centrado en riesgos específicos en ciertos países, en lugar de abordar la experiencia del riesgo y el daño en su conjunto y desde una perspectiva comparativa.

1 El campo cuantitativo en España se financió a través del Proyecto CSO2013-47304-R del MINECO.

2 En el proyecto Net Children Go Mobile han participado Dinamarca, Italia, Reino Unido, Rumanía, Bélgica, Irlanda, Portugal y España. El campo cuantitativo en España se financió a través del Proyecto CSO2013-47304-R del MINECO. 
Una excepción notable es el proyecto EU Kids Online, que entrevistó a más de 25.000 niños y niñas de 9 a 16 años y a sus padres y madres en 25 países europeos.

Este estudio presenta el análisis de los resultados más significativos en España del mencionado proyecto Net Children Go Mobile en basándose en las cuestiones que enumeramos a continuación.

\section{Riesgos y daños}

Uno de los mayores hallazgos de este proyecto es que las experiencias de riesgo online no conducen necesariamente al daño, tal y como indicaron los propios menores (Livingstone et al., 2011). De hecho, la investigación EU Kids Online mostró que los niños y las niñas que se encuentran con mayor número de riesgos en línea no son necesariamente quienes sufren consecuencias más dañinas; por el contrario, normalmente son ellos quienes demuestran más habilidades y desarrollan más resiliencia. Los niños y las niñas que están menos expuestos tanto a las oportunidades como a los riesgos tienden a sentirse más molestos y preocupados cuando sufren una experiencia online negativa (ibídem; ver también Livingstone, Hasebrink, \& Görzig, 2012). Tanto entre los mayores, expuestos a más riesgos pero más resistentes, como entre los pequeños, que participan en menos actividades y se enfrentan, por tanto, a menos riesgos, la vulnerabilidad online y offline van de la mano.

\subsection{Bullying}

Si bien es una cuestión recurrente tanto en la investigación como en las agendas públicas y políticas, no hay una definición estandarizada de lo que es el ciberbullying dado que el fenómeno en sí mismo está en permanente evolución (Schrock \& Boyd, 2008; ver también Levy et al., 2012). La mayoría se basan en la definición del propio bullying y sus componentes. El "bullying" ha sido descrito como una forma de agresión que es (a) intencional, (b) repetitiva, y que (c) implica una desigualdad de poder entre víctima y agresor. Consecuentemente, el ciberbullying se define como una agresión intencional y repetida utilizando cualquier tipo de aparato tecnológico, como internet o el teléfono móvil.

Aunque el ciberbullying es una actividad intencional y repetida que busca hostigar o ridiculizar a otra persona, e igualmente implica la desigualdad de poder que se ha mencionado, la investigación ha mostrado que las especificidades de la comunicación online o móvil refuerza los rasgos del bullying tradicional añadiéndole nuevos elementos. Por ejemplo, el anonimato "puede incrementar la naturaleza amenazadora de un acto de ciberbullying, o el sentido de impotencia de la víctima resultante" (Levy et al., 2012, p. 11), e igualmente incrementar el desequilibrio de poder entre la víctima y el agresor. El anonimato, sin embargo, puede no ser exclusivo de las comunicaciones en línea (y de hecho, el ambiente escolar puede facilitar que haya actos de bullying anónimos, como Levy y sus colegas señalan). Además, mientras un acto de ciberbullying puede no repetirse en el tiempo necesariamente (Levy et al., 2012), las propiedades de los públicos mediados -persistencia, trazabilidad, replicabilidad y audiencias invisibles (Boyd, 2008)- amplifican potencialmente la duración del ciberbullyingy sus consecuencias dañinas, ya que audiencias más amplias pueden verse implicadas.

La investigación precedente ha mostrado que, si bien el ciberbullying es menos común que el bullying offline (Livingstone et al., 2011; Ybarra \& Mitchel, 2014), es una experiencia muy angustiosa y dañina (Livingstone et al., 2011). El desplaza- 
miento de los espacios offline a los online implica que las fronteras de espacio y tiempo van perdiendo su sentido: no se puede abandonar un espacio y suponer que el bullying terminará; de hecho, el bullying es más susceptible de ocurrir también tras la escuela, en diversas plataformas (Kernaghan \& Elwood, 2013). Además, comparadas con las formas de bullying cara a cara, las fronteras entre los roles de víctima, agresor y espectadores son más difíciles de trazar en el bullying online (Lampert \& Donoso, 2012).

\subsection{Mensajes sexuales}

Los menores están utilizando internet y los teléfonos móviles como parte de sus interacciones y exploraciones sexuales (Lenhart, 2009; Livingstone et al., 2011). Esta práctica ha sido denominada "sexting" (a partir de las palabras sex y texting), y ha sido definida de diversas maneras. Una aproximación restringe el sexting al intercambio de imágenes por medio del teléfono móvil. Lenhart define sexting como "crear, compartir y difundir imágenes de desnudos o semidesnudos sexualmente sugerente" de sí mismo o de alguien a quien se conoce, a través del móvil (2009, p. 2), excluyendo por tanto textos sexualmente insinuantes así como el resto de las plataformas de comunicación. La encuesta EU Kids Online, por el contrario, adoptó una noción del sexting más inclusiva, que tiene en cuenta las imágenes y los textos, y considera todo tipo de comunicación online más allá del uso de los teléfonos móviles (Livingstone et al., 2011).

El estudio Pew Internet Study (Lenhart, 2009) identifica tres supuestos básicos de sexting, cuando el intercambio de imágenes sexuales ocurre: (a) como parte de la experimentación adolescente con la identidad sexual y la intimidad, aunque sus protagonistas no sean todavía sexualmente activos; (b) entre dos compañeros, como parte de una relación sexual; c) como el prólogo de una actividad sexual, entre dos personas que aún no tienen una relación, de las cuales al menos una sí querría tenerla. De hecho, la mayoría del sexting puede ser contextualizado dentro de una relación de pares, como forma de "moneda de cambio" en la relación (Lenhart, 2009, p. 8). Sin embargo, las especificidades tecnológicas y la disponibilidad social de las TIC puede amplificar las fronteras, significados y audiencias del sexting. imágenes y textos intercambiados en el contexto de relaciones románticas, mediante mensajería instantánea (WhatsApp, Snapchat, etc.) o redes sociales pueden ser fácilmente distribuidas, publicadas en más espacios online y por tanto ser compartidas con audiencias más amplias. Por tanto, los mensajes sexuales pueden tener consecuencias no intencionadas y pueden convertirse en experiencias desagradables o problemáticas para algunos menores. La investigación precedente sostiene que el intercambio de imágenes, mensajes o invitaciones sexualmente explícitos está ligado al hostigamiento y el bullying, y por tanto conduce a una forma de “ciberbullying sexual” (Kofoed \& Ringrose, 2012; Ringrose, Gill, Livingstone, \& Harvey, 2012).

\subsection{Contacto con personas desconocidas}

Una de las mayores fuentes de ansiedad en relación con las comunicaciones online de los jóvenes se refiere a lo que en inglés se define como stranger danger, esto es, la idea de que la gente joven puede conocer a alguien a través de internet, ser persuadida para contactar offline y terminar siendo víctima de abusos en ese encuentro cara a cara. De hecho, investigaciones precedentes han sugerido que "conocer extraños" puede abarcar diversas circunstancias y experiencias, que no pueden ser asumidas como universalmente problemáticas (Barbovschi, Marinescu, Velicu, Anca \& Laszlo, 2012; Ito et al., 2009); al mismo tiempo, estudios 
previos muestran que el riesgo de ser dañado en un encuentro cara a cara con alguien que se ha conocido online es bajo (Livingstone et al., 2011).

Una de las principales razones radica en el modo en el que funciona la sociabilidad en línea, a través de la cual los menores tienden a extender su red de contactos online activando "vínculos latentes" (por ejemplo, personas con las que comparten amigos, hobbies o ubicación), más que buscando a personas con las que no guardan conexión alguna en el entorno offli$n e$. De hecho, la mayoría de los encuentros cara a cara con personas previamente contactadas online son con "amigos de amigos" y no con completos desconocidos (Barbovschi et al., 2012). Por tanto, el primer paso es entender cómo funciona la comunicación en línea y el proceso de contacto con personas que se han conocido por internet, y seguidamente identificar cómo se pasa a encontrarse offline con alguien que se conoció online.

\subsection{Imágenes sexuales}

La pornografía, y más concretamente, la influencia negativa que ejerce la pornografía en los menores, es un objeto de estudio controvertido. La creencia de que la ausencia de censura y, en consecuencia, las facilidades para que el contenido pornográfico circule por internet haya llevado la pornografía de "debajo de la cama" a la pantalla genera ansiedades públicas (Rovolis \& Tsaliki, 2012, p. 173). Sin embargo, la ubicuidad de los contenidos sexuales en internet se ha abordado en múltiples estudios (ver, entre otros, Ey \& Cupit, 2011) y, por ejemplo, el proyecto EU Kids Online reveló que uno de cada cuatro menores se ha encontrado con contenido pornográfico, y solo el $14 \%$ se han encontrado, accidental o intencionalmente, con imágenes sexuales online (Livingstone et al., 2011). Igualmente, los datos también mostraron que mientras que ver imágenes sexuales es más común entre chicos y adolescentes de mayor edad, los niños más pequeños y las chicas tienden en mayor medida a disgustarse con los contenidos con los que se encuentran.

\subsection{Otros contenidos inapropiados}

Internet ha permitido la circulación sin precedentes de una ingente cantidad de contenidos generados por los propios usuarios y usuarias, que no son producidos ni distribuidos masivamente por empresas, sino que son realizados por personas particulares (UGC, User-Generated Content). Si bien es cierto que la creación y la posibilidad de compartir contenidos es una de las oportunidades fundamentales que ofrece la red, y un elemento muy importante dentro de los procesos de alfabetización digital, hay ciertos contenidos generados por usuarios que podrían considerarse problemáticos: los que promueven desórdenes alimenticios; comportamientos autolesivos, o consumo de drogas, o los materiales online que promueven la discriminación y la violencia contra ciertos grupos están entre los principales ejemplos de contenidos negativos generados por usuarios. Aunque hay ciertas evidencias de que la exposición a este tipo de mensajes es relativamente común entre los menores (Livingstone et al., 2011), esta cuestión ha recibido menos atención por parte de legisladores e investigadores que otras como el bullying, el sexting, el contacto con extraños o la pornografía. 


\subsection{Otros Riesgos}

Incluye riesgos comerciales, como perder dinero como consecuencia de ser víctimas de fraudes online, riesgos técnicos, como virus o software malintencionado; y riesgos relacionados con el mal uso de la información personal. Esto último comprende ser víctima del pirateo de la cuenta de correo electrónico o el perfil en redes sociales; el uso inadecuado de información personal y de fotos de la víctima que un tercero se atribuye (por ejemplo, mediante la creación de perfiles falsos); y personas que se hacen pasar por otras, o catfishing.

\section{Método}

Los resultados que presentamos en este trabajo corresponden a una recogida de datos llevado a cabo en España mediante encuesta a una muestra de 500 menores usuarios y usuarias de internet de entre 9 y 16 años y a su padre o a su madre. Este trabajo de campo se desarrolló entre abril y junio del 2015. En cada casa se entrevistó a aquel de los progenitores que estuviera más implicado en la actividad online del menor.

Las características más relevantes de la encuesta fueron:

- Un test cognitivo con ocho niños y niñas de diversos grupos de edad (9-10, 11-12, 13-14, 15-16), para comprobar la comprensión y las reacciones de los y las menores a las preguntas.

- Selección aleatoria estratificada de 500 menores (de entre 9 y 16 años) todos ellos y ellas usuarios de internet.

- Administración del cuestionario en la propia vivienda, cara a cara con una sección auto-administrada para las cuestiones más sensibles.

- Administración del cuestionario al padre o madre del o la menor, aquel o aquella que estuviera más implicado/a en la actividad en internet del menor.

- A los padres y madres se les preguntó sobre su uso de internet y de dispositivos móviles y sus estrategias de mediación, así como cuestiones socio-demográficas y su nivel educativo.

\section{Resultados: Percepción general del riesgo y del daño}

La medición de las experiencias de riesgo y daño en línea está presente en la metodología y el marco operativo de $E U$ Kids Online (Livingstone et al., 2011). Por eso el daño fue medido de forma subjetiva en función de lo que indicaban las respuestas de los niños y las niñas ante las experiencias de riesgo. Cerca del 18\% de los menores (ver tabla 1) dicen que se han sentido molestos por algo que han visto en internet a lo largo del año pasado. Aunque sigue siendo una minoría, este porcentaje es mayor que el constatado por la encuesta EU Kids Online de 2010. Ni las diferencias en función del género ni de la edad pueden considerarse sustanciales: el $17 \%$ de los chicos y el $18 \%$ de las chicas afirman haberse sentido molestos por alguna cuestión relacionada con internet. Por franjas de edad, aquella en la que la proporción de respuestas afirmativas es menor es la de los más jóvenes, de 9 y 10 años, pero solo hay dos puntos porcentuales de diferencia con respecto a la franja con más porcentaje de menores que declaran experiencias negativas (19\% para la franja de 11 y 12 años). Bastante más marcadas resultan las diferencias en función de los estudios de los progenitores. Los niños y las niñas cuyos padres tienen un nivel menor de estudios son más propensos a haber experimentado en internet algo que les haya molestado. 
Tabla 1. Menores que han sufrido experiencias online que les han molestado por género y edad ${ }^{3}$.

\begin{tabular}{|l|c|}
\hline \multicolumn{1}{|c|}{ Género y edad } & \% sobre todos los menores que usan internet \\
\hline Niños & 17 \\
\hline Niñas & 18 \\
\hline $9-10$ años & 17 \\
\hline $11-12$ años & 19 \\
\hline $13-14$ años & 18 \\
\hline $15-16$ años & 18 \\
\hline & $\mathbf{1 8}$ \\
\hline
\end{tabular}

Fuente: Elaboración propia. Base: Todos los menores que usan internet.

En general, respecto a la incidencia de las experiencias online que han resultado molestas no existen diferencias sustanciales entre los menores que utilizan diariamente la tableta (18\%) y el smartphone (17\%). Y lo cierto es que tampoco hay diferencias significativas entre ellos y quienes no utilizan a diario dispositivos móviles para navegar (16\%). Hay algunas pequeñas variaciones por sexo: los chicos son más susceptibles de haber sufrido experiencias molestas a través del smartphone, y las chicas, a través de sus tabletas.

De aquí podríamos sacar dos conclusiones. Una, se puede hablar de un ligero incremento en la probabilidad de que los menores afirmen que algo les ha molestado, lo que puede asociarse al uso de smartphones y tabletas para acceder a internet. Y dos, esta asociación refuerza la denominada "teoría del uso": cuanto más usan internet los menores, disfrutan de más oportunidades, pero también se exponen a más experiencias de riesgo.

\subsection{Bullying}

En torno a un tercio de niños y niñas han experimentado alguna forma de bullying online u offline. El $12 \%$ afirmaron estar "muy" disgustados, y el 12\% "un poco" disgustados con lo que había ocurrido. La experiencia del bullying está levemente sesgada por género; es más probable entre las chicas haberlo experimentado (35\%) y haberse disgustado por ello (26\%) que entre los chicos, de los cuales el $29 \%$ respondió haberlo sufrido, y el $22 \%$ haberse disgustado. También hay variaciones en función de la edad, confirmando una diferencia entre las franjas de menor edad, y la de los niños y las niñas de 15 y 16 años. En esta franja la incidencia del bullying parece disminuir, y también disminuye a la mitad el porcentaje de menores que dicen haberse sentido disgustados por esas experiencias. Así, los menores de más edad declaran tasas de daño mucho más moderadas que el resto ( $6 \%$ frente a la media, $12 \%)$.

3 Se han suprimido los decimales de las medias que se señalan en las tablas. 
La convergencia mediática, los riesgos y el daño online que encuentran los menores

Tabla 2. Modos en los que los niños y las niñas han sufrido bullying en los últimos 12 meses.

\begin{tabular}{|c|c|c|c|c|c|}
\hline $\begin{array}{c}\text { Modos de bullying } \\
\text { (\%)Porcentajes sobre la base de todos los menores que usan internet }\end{array}$ & 9-10 años & 11-12 años & 13-14 años & 15-16 años & TOTAL \\
\hline En persona, cara a cara & 27 & 27 & 27 & 20 & 25 \\
\hline Llamadas de teléfono móvil & 0 & 1 & 2 & 3 & 1 \\
\hline A través de mensajes en mi teléfono (SMS o MMS) & 0 & 1 & 2 & 3 & 1 \\
\hline En una red social (Twiter, Facebook, Tuenti, etc.) & 1 & 4 & 6 & 8 & 4 \\
\hline En una plataforma (Youtube, Instagram, Flickr) & 2 & 3 & 6 & 2 & 3 \\
\hline Por mensajería instantánea (MSN, WhatsApp, Skype) & 2 & 4 & 7 & 9 & 5 \\
\hline En un chat & 3 & 6 & 4 & 2 & 4 \\
\hline Correo electrónico & 0 & 0 & 0 & 0 & $\mathbf{0}$ \\
\hline Página de apuestas & 0 & 0 & 0 & 0 & $\mathbf{0}$ \\
\hline Otros & 0 & 0 & 0 & 0 & 1 \\
\hline Alguna forma de bullying a través de internet o dispositivos móviles & 8 & 13 & 14 & 15 & 12 \\
\hline
\end{tabular}

Fuente: Elaboración propia. Base: Todos los menores que usan internet.

Si bien el 12\% de los menores afirman haber sido víctimas de acoso a través de internet o dispositivos móviles, el ciberbullying no es el modelo dominante de agresión. De hecho, el porcentaje de menores que se consideran víctimas de bullyingen persona, cara a cara, supone más del doble de quienes han sufrido ciberbullying (12\%). Las vías a través de las cuales más habitualmente se concreta el ciberbullying son la mensajería instantánea, que en nuestro entorno actualmente se asimila al WhatsApp (53\%), las redes sociales (4\%), y los chats (4\%). Con respecto a la relación entre la incidencia del acoso online y el offline hay ciertas diferencias en función de la edad, si bien son pequeñas. Los menores más jóvenes indican mayor prevalencia del bullying offline sobre el online: el acoso sufrido cara a cara se mantienen en el 27\% entre los 9 y los 14 años para pasar al 20\% para la franja de 15 y 16 años (ver tabla 2). Por el contrario, la incidencia general del ciberbullying aumenta muy progresivamente a media que lo hace la edad de los adolescentes. Es en la franja de 15 y 16 años donde sufren con más frecuencia los casos de ciberbullying mediante redes sociales, mensajería instantánea, llamadas o mensajes que se reciben en teléfono móvil.

La forma de ejercer bullying más habitual es cara a cara. El 19\% de las chicas y chicos encuestados afirman haber acosado a otros en un contexto offline, mientras la combinación de todas las formas de ciberbullying consideradas, reconociendo haber utilizado algún canal de comunicación online para consumar el acoso, aparece en el 8\% de los menores encuestados, fundamentalmente a través de las redes sociales, mensajería instantánea y chats. La mayor incidencia de bullying declarado, tanto online como offline aparecen en la franja de 13 y 14 años, superando con mucho las medias de acoso realizado a través de mensajes, redes, plataformas, mensajería instantánea y, en general, cualquiera de las opciones consideradas.

Cotejando la incidencia del bullyingy del ciberbullying es reseñable que en cinco años los porcentajes de niños y niñas que dicen haber sido víctimas de acoso se hayan duplicado en absolutamente todas las franjas de edad (ver tabla 3) y por toda 
clase de medios (ver tabla 4). En este sentido, la cifra media total refleja una realidad que puede considerarse preocupante: si en 2010 el 15\% de menores de 9 a 16 años declaraban haber sufrido bullying en cualquiera de sus variedades, 5 años después esta cifra ha subido al $31 \%$. Con respecto a la proporción de menores que declaran haber ejercido bullying contra otros, la cifra aumenta en una proporción similar.

Con todo, y aun sin ánimo de subestimar la importancia cuantitativa de estas cifras y del retrato que dibujan de una infancia y adolescencia enfrentada a problemas en la gestión de la convivencia, la duplicación de la población que dice haber sufrido acoso ha de entenderse en un contexto de preocupación social creciente respecto a las situaciones de abuso y desprotección de la infancia. Las iniciativas institucionales de cara a la sensibilización y el amparo de los menores afectados están relacionadas con una agenda mediática en la que términos como acoso escolar, bullying, ciberbullying o abusos entre menores son relativamente habituales. Hay una mayor atención pública al fenómeno, más campañas, más sensibilidad en definitiva. Y esto puede estar relacionado con mayores facilidades para identificar situaciones de abuso y acoso por parte de quienes las sufren, que quizá anteriormente sentían que el acoso escolar estaba normalizado o ni siquiera era considerado problemático (“cosas de niños”).

Tabla 3. Menores que han sufrido bullyingo ciberbullying.

\begin{tabular}{|l|c|c|}
\hline \multicolumn{1}{|c|}{$\begin{array}{c}\text { Genero/Edad } \\
\text { \% sobre todos los menores que usan internet }\end{array}$} & 2015 & 2010 \\
\hline Niños & 35 & 13 \\
\hline Niñas & 28 & 17 \\
\hline $9-10$ años & 33 & 12 \\
\hline $11-12$ años & 32 & 13 \\
\hline $13-14$ años & 33 & 16 \\
\hline $15-16$ años & 28 & 18 \\
\hline TOTAL & 32 & 15 \\
\hline
\end{tabular}

Fuente: Elaboración propia. Base: Todos los menores que usan internet.

Además, también es necesario tener en cuenta las dificultades inherentes a la definición del acoso y a lo que se considera, o no, como tal, y a la estrecha relación con la vivencia personal de cada una de las personas que se consideran víctimas de un abuso: bajo la etiqueta de bullying caben desde situaciones vejatorias objetiva e indiscutiblemente graves, también hay lugar para otras situaciones que dependiendo de la sensibilidad y la resiliencia de cada víctima revisten una gravedad relativa. 
La convergencia mediática, los riesgos y el daño online que encuentran los menores

Tabla 4. Modos en los que los menores han sufrido bullying en los últimos 12 meses.

\begin{tabular}{|l|c|c|}
\hline \multicolumn{1}{|c|}{$\begin{array}{c}\text { Modos de sufrir bullying últimos 12 meses } \\
\text { \%) sobre todos los menores que usan internet }\end{array}$} & $\mathbf{2 0 1 5}$ & $\mathbf{2 0 1 0}$ \\
\hline Cara a cara & 25 & 10 \\
\hline En internet & 8 & 4 \\
\hline Por teléfono (llamadas o mensajes) & 6 & 2 \\
\hline Online u offline & 32 & 16 \\
\hline
\end{tabular}

Fuente: Elaboración propia. Base: Todos los menores que usan internet.

Con respecto al papel que juegan las tecnologías de la comunicación en este incremento en el número de personas que se autodefinen como víctimas del acoso, cabe señalar que el incremento de los casos de acoso cara a cara es, en este lapso de cinco años, notablemente mayor incluso que el incremento de los casos de ciberbullying concretados a través de internet.

\subsection{Mensajes sexuales}

En general, el 31\% de los menores han recibido mensajes sexuales de algún tipo, y el 14\% dice haberse sentido "muy" (5\%) o "un poco" (9\%) disgustados como consecuencia. La experiencia de recibir mensajes sexuales es algo diferente en función del género. El porcentaje de niñas que afirma haberlos recibido es del 28\%, y entre los niños asciende al 35\%. Pero la probabilidad de sentirse disgustado por esa experiencia también es distinta: es más probable que las chicas se sientan "muy" o "un poco" (7 y 10\%) molestas por el sexting que los chicos, entre los cuales el 3 y el $8 \%$ se sintieron "muy" o "un poco" molestos. Más del doble de chicos que de chicas afirman haber recibido mensajes sexuales sin que ello les disgustara. El sexting se incrementa con la edad: el 19\% de los niños y las niñas de 11 y 12 dicen haber recibido mensajes de este tipo, y el porcentaje llega hasta el 34\% para la franja de 13 y 14 años, y al 42\% para la franja de 15 y 16 años. Pero también varía el porcentaje de menores que se sienten afectados por esta experiencia. Entre los menores de 11 y 12 años, el $11 \%$, y en la franja de 13 y 14 años, el 20\%, se sintieron "muy" o "un poco" disgustados, pero en la franja de 15 y 16 años solo hay un $10 \%$ de chicos y chicas disgustados tras haber recibido mensajes sexuales. Las diferencias en función de los estudios de los padres no resultan relevantes, aunque los niños y las niñas cuyos padres tienen menos estudios reportan en mayor porcentaje haber recibido mensajes sexuales.

Los menores recibieron mensajes sexuales básicamente a través de las redes sociales (6\%) y las plataformas (5\%), pero sobre todo a través de los servicios de mensajería instantánea (ver tabla 5). De hecho, el 15 \% de los menores afirmó haber recibido mensajes sexuales por esa vía, y el porcentaje se eleva al 19\% y 35\% respectivamente cuando se trata de menores en las franjas de edad de 13 y 14 años, y 15 y 16 respectivamente. 
Tabla 5. Modos en los que los menores recibieron mensajes sexuales en los últimos 12 meses.

\begin{tabular}{|c|c|c|c|c|}
\hline $\begin{array}{l}\text { Modos de recibir mensajes sexuales } \\
\text { \% sobre la base de todos los menores que usan internet }\end{array}$ & $\begin{array}{l}11-12 \\
\text { años }\end{array}$ & $\begin{array}{l}13-14 \\
\text { años }\end{array}$ & $\begin{array}{l}15-16 \\
\text { años }\end{array}$ & TOTAL \\
\hline Llamadas de teléfono móvil & 1 & 1 & 4 & 1 \\
\hline A través de mensajes en mi teléfono (SMS o MMS) & 0 & 1 & 2 & 1 \\
\hline En una red social (Tuenti, Facebook, ...) & 3 & 9 & 11 & 6 \\
\hline En una plataforma (Youtube, Instagram, Flickr) & 3 & 10 & 8 & 5 \\
\hline Por mensajería instantánea (MSN, WhatsApp, Skype) & 8 & 19 & 35 & 15 \\
\hline En un chat & 5 & 4 & 2 & 3 \\
\hline Por correo electrónico & 0 & 2 & 1 & 1 \\
\hline En una comunidad de juegos & 0 & 0 & 0 & 0 \\
\hline
\end{tabular}

Fuente: Elaboración propia. Base: Todos los menores de 11 a 16 años que usan internet.

Se observa un aumento extraordinario en el porcentaje de menores que han recibido mensajes sexuales. Si en 2010 uno de cada 10 niños y niñas de las franjas de edad consideradas, 11 a 16 años, decía haber recibido mensajes de este tipo, en 2015 son prácticamente uno de cada tres quienes responden afirmativamente a esta pregunta.

En cuanto al género se refiere, si en 2010 eran muchos más los niños los que habían recibido mensajes sexuales, en 2015 se ha invertido la proporción: son muchos más, tanto ellos como ellas quienes han respondido afirmativamente, pero el porcentaje entre las niñas supera hoy a los niños (ver tabla 6).

Tabla 6. Género y Edad de los menores que han recibido mensajes sexuales.

\begin{tabular}{|l|c|c|}
\hline \multicolumn{1}{|c|}{$\begin{array}{c}\text { Género y edad } \\
\text { \% sobre la base de todos los menores que usan internet }\end{array}$} & $\mathbf{2 0 1 5}$ & $\mathbf{2 0 1 0}$ \\
\hline Niñas & 35 & 7 \\
\hline Niños & 28 & 11 \\
\hline $11-12$ años & 19 & 3 \\
\hline $13-14$ años & 34 & 10 \\
\hline $15-16$ años & 42 & 13 \\
\hline TOTAL & 30 & 10 \\
\hline
\end{tabular}

Fuente: Elaboración propia. Base: Todos los menores de 11 a 16 años que usan internet.

Con respecto a las vías a través de las cuales se han vehiculado esos mensajes, aumentan los recibidos a través de móviles, chats, y sobre todo redes sociales y mensajería instantánea, en línea con los niveles de equipamiento tecnológico y con los hábitos y rutinas de navegación correspondientes a la actualidad. 


\subsection{Contacto con personas desconocidas}

Uno de cada cinco menores (21\%) ha contactado online con personas que no conocía en persona. Si bien se aprecian ciertas variaciones en función del género, con más niñas que niños respondiendo afirmativamente a esta cuestión, donde realmente se aprecian diferencias es entre franjas de edad: el contacto online con personas desconocidas se incrementa con los años. De manera notable, en el paso de los 11-12 a los 13-14 años, el porcentaje de menores que contactan online con alguien a quien no conocen se triplica. Las diferencias en función de los estudios de los padres también son considerables, con menos probabilidad de contactar online con desconocidos a medida que se incrementa el estatus educativo de las familias de las que provienen.

El contacto con personas que se conocen a través de internet, per se, no tiene por qué ser negativo o implicar riesgos. De hecho, en ocasiones proporciona a los menores la oportunidad de compartir intereses y aficiones (Ito et al., 2009). Por otra parte, no todos los contactos online forzosamente conducen a encuentros offline, y lo que es más importante, no todo encuentro cara a cara con alguien que se conoció en internet tiene consecuencias nocivas.

El 11\% de los menores afirman haber conocido cara a cara a alguien que previamente conocían por internet, y el 1\% (uno de cada diez) resultó "muy" o "un poco" disgustado con la experiencia. Apenas existen diferencias entre niños y niñas que participaron en este tipo de encuentros, y en cómo se sintieron tras estos encuentros. La probabilidad de encontrarse offline con contactos online se incrementa con la edad, del $2 \%$ registrado en la franja de 9 y 10 años al $25 \%$ para la franja de 15 y 16 años (ver tabla 7).

Considerando que la relación entre riesgo y daño es compleja y no lineal, incluso en situaciones en las que encontrarse físicamente con contactos online no resulte dañina, siempre resultan oportunas las campañas que buscan concienciar al respecto, así como programas de seguridad que promueven una gestión responsable de los contactos a través de internet. Los menores que entraron en contacto con quienes finalmente llegaron a conocer cara a cara fueron fundamentalmente a través de redes sociales (6\%) y mensajería instantánea (6\%). En menos proporción se sitúan las plataformas como Youtube, Instagram y Flickr y los chats (3\% en ambos casos). Hay notables diferencias por edad: los adolescentes de 15 y 16 años son más propensos a contactar online, y tienden a hacerlo en redes sociales (16\%), mensajería instantánea (MSN, WhatsApp, Skype) (13\%), plataformas (9\%), y en mucha menor medida mensajes recibidos en un chat (4\%) o llamadas telefónicas (3\%).

Si bien en cinco años (2010-2015) ha aumentado la prevalencia del hábito de conocer en persona a alguien con quien el contacto previo solo había sido online -en términos absolutos, los menores que afirman haberlo experimentado eran el 9\% en 2010 y el 11\% en 2015-, se aprecian ciertas diferencias en la distribución por edades. Se advierte cómo en las franjas de niños más jóvenes el porcentaje de quienes han conocido offline a un contacto previo desciende a la mitad. Ya en 2010 entre los más jóvenes era entre quienes, de un modo lógico, menos peso estadístico tenía esta práctica, pero destaca comprobar que mientras entre los mayores aumenta el porcentaje de quienes incurren en una práctica potencialmente arriesgada, los pequeños parecen haber interiorizado mensajes de precaución o prudencia al respecto. 
Tabla 7. Menores que contactaron con personas que habían conocido online. Evolución 2010-2015.

\begin{tabular}{|l|c|c|}
\hline \multicolumn{1}{|c|}{ \% sobre la base de todos los menores que usan internet } & 2015 & 2010 \\
\hline Niños & 12 & 9 \\
\hline Niñas & 11 & 9 \\
\hline $9-10$ años & 2 & 5 \\
\hline $11-12$ años & 2 & 4 \\
\hline $13-14$ años & 18 & 8 \\
\hline $15-16$ años & 25 & 7 \\
\hline & 11 & 9 \\
\hline
\end{tabular}

Fuente: Elaboración propia. Base: Todos los menores que usan internet.

\subsection{Imágenes sexuales}

En general, solo uno de cada tres menores expuestos a contenido sexual online manifestó sentirse molesto tras esta experiencia, aunque existe una considerable variación intercultural (ibídem). A partir de estos hallazgos Rovolis y Tsaliki (2012) concluyen que, tal y como las aproximaciones desde los estudios culturales han estado defendiendo durante un tiempo (Attwood \& Smith, 2011; Buckingham \& Bragg, 2004), la preocupación por los efectos negativos de la pornografía se exagera en los medios de comunicación.

Más de la mitad de los menores (52\%) afirma que ha visto imágenes sexuales, haya sido en formato online u offline (ver tabla 8). Ver imágenes sexuales está parcialmente relacionado con el género -con el $48 \%$ de chicas que declaran esta experiencia frente al 56\% de los chicos- y de un modo más consistente, relacionado con la edad: el $70 \%$ de los adolescentes de más edad ha visto imágenes sexuales, comparado con el $36 \%$ de los niños y las niñas más pequeñas.

Habiendo experimentado con contenidos sexuales online u offline más de la mitad de los menores, el $20 \%$ de ellos se sintió molesto con esta experiencia, y únicamente el 7\%, dijo sentirse muy molesto al respecto. Las niñas expuestas a imágenes sexuales son más propensas que los niños a sentirse "un poco" disgustadas (15\%) por lo que han visto. Los porcentajes de niños y niñas muy disgustados son equivalentes ( 6 y $7 \%$ respectivamente).

La relación entre riesgo y daño varía con la edad: más de la mitad de los niños y las niñas de 9 y 10 años que vieron contenidos sexuales se sintieron "muy" o "un poco" disgustados por ello; menos de uno de cada cuatro de los y las menores de 15 y 16 años que vieron contenidos sexuales dijo sentirse disgustado por ello.

La televisión y las películas (31\%) siguen siendo la vía más habitual de ver imágenes sexuales, seguidas por las revistas y vídeos (16\%), los pop-ups en internet (13\%), y los vídeos en plataformas, tipo Youtube (12\%). La tendencia a que la exposición se incremente con la edad es notable. A medida que los niños y las niñas van haciéndose mayores, es más probable que vean imágenes sexuales en todos los medios. La exposición a imágenes sexuales sigue siendo una experiencia bastante 
común, ya sea offline como online. Mientras los chicos mayores tienden a ser más resilientes al respecto, los más jóvenes y las chicas se sienten más vulnerables a las consecuencias negativas de los contenidos sexuales.

Al igual que se ha señalado al describir la evolución de otros riesgos, la proporción de menores que han visto imágenes sexuales ha aumentado de un modo exponencial en los últimos años. En 2015 la mitad de los chicos y chicas de 9 a 16 afirma haber estado en contacto con estos contenidos, cuando en 2010 solo el 11\% de los entrevistados respondió positivamente a esa pregunta. Con todo, se mantiene una distribución en función de edad, género y nivel de estudios de los padres que puede ser considerada más o menos equivalente: las franjas que entonces decían haber visto imágenes sexuales en mayor proporción -más niños que niñas y, obviamente, adolescentes de 15 y 16 años, sin que las diferencias en función de los estudios de los progenitores resultaran importantes- son las mismas en la actualidad.

Tabla 8. Número de menores que han visto imágenes sexuales.

\begin{tabular}{|l|c|c|}
\hline \multicolumn{1}{|c|}{$\begin{array}{c}\text { Género y edad } \\
\text { \% sobre la base de todos los menores que usan internet }\end{array}$} & $\mathbf{2 0 1 5}$ & $\mathbf{2 0 1 0}$ \\
\hline Niños & 56 & 13 \\
\hline $9-10$ años & 49 & 8 \\
\hline $11-12$ años & 50 & 8 \\
\hline $13-14$ años & 57 & 15 \\
\hline $15-16$ años & 70 & 17 \\
\hline & 52 & 11 \\
\hline
\end{tabular}

Fuente: Elaboración propia. Base: Todos los menores que usan internet.

Es innegable que internet, y en particular el internet móvil y los dispositivos de uso personal, más complicados de controlar por parte de las familias, han facilitado el acceso a contenidos que en muchas ocasiones pueden considerarse incluso pornográficos. A este respecto, cabe subrayar el modo en el que el acceso a imágenes sexuales por medio del teléfono móvil se ha multiplicado por 10 en los últimos cinco años, y el acceso a través de páginas web se ha duplicado ampliamente. Como se ha mencionado antes, esto está relacionado con el aumento de la dotación de teléfonos móviles y del acceso, en conjunto, a todos los recursos de internet.

No obstante, es importante atender a los incrementos en los accesos a imágenes sexuales que se han producidos por vías en principio ajenos a internet. Así, en cinco años y pese al evidente incremento en el porcentaje de menores que han visto imágenes sexuales, quienes han accedido a estos contenidos vía revista o libro, o televisión, película o DVD, lejos de ser menos, son muchos más. 


\subsection{Otros contenidos inapropiados}

El 32\% de los menores afirma haber visto online contenidos inapropiados y potencialmente dañinos (ver tabla 9). Esta exposición se ha incrementado desde 2010, año en el que el 19\% de los españoles entre 11 y 16 años se habían encontrado con uno o más tipos de estas páginas.

Tabla 9. Menores (11-16 años)4 que han visto en páginas web contenidos potencialmente dañinos por edad.

\begin{tabular}{|c|c|c|c|c|}
\hline $\begin{array}{l}\text { Edad } \\
\% \text { sobre la base de todos los menores que usan internet }\end{array}$ & $\begin{array}{l}11-12 \\
\text { años }\end{array}$ & $\begin{array}{l}\text { 13-14 } \\
\text { años }\end{array}$ & $\begin{array}{l}\text { 15-16 } \\
\text { años }\end{array}$ & TOTAL \\
\hline Sobre formas para lesionar a otros o autolesionarse & 13 & 18 & 19 & 17 \\
\hline Sobre formas de suicidarse & 3 & 12 & 14 & 10 \\
\hline Páginas que promueven desórdenes alimenticios (anorexia, bulimia...) & 8 & 14 & 21 & 14 \\
\hline $\begin{array}{l}\text { Con mensajes de odio que atacan a ciertos grupos o individuos (ej. racismo o } \\
\text { ataques contra una religión) }\end{array}$ & 14 & 13 & 29 & 18 \\
\hline Sobre experiencias de drogas & 2 & 11 & 16 & 10 \\
\hline Alguno de ellos & 23 & 32 & 42 & 32 \\
\hline
\end{tabular}

Fuente: Elaboración propia. Base: Todos los menores de 11 a 16 años que usan internet.

Aunque hay algunas diferencias entre los distintos grupos de edad, los menores se encuentran con más frecuencia con mensajes que promueven el odio o los ataques contra personas o grupos en función de su raza, religión u otras cuestiones (18\%), mensajes que indican cómo lesionar a otros o autolesionarse (17\%) y contenidos proanorexia o probulimia (14\%) que con páginas relacionadas con la experiencia del consumo de drogas o con el suicidio. No obstante, y aunque se trate de un porcentaje relativamente reducido, es importante señalar que el $10 \%$ de los menores españoles se ha encontrado con páginas en las que se hablaba sobre formas de suicidarse. La exposición a contenidos inapropiados se incrementa con la edad: el 23\% de los niños y las niñas de 11 y 12 años se ha encontrado con al menos un tipo de ellos, frente al $42 \%$ de aquellos que tienen 15 y 16 años.

El acceso a contenidos inadecuados se ha visto incrementado, de 2010 a 2015 (ver tabla 10), lo cual indica que actualmente es más probable, y también más fácil, acceder a páginas generadas por usuarios en los que se comparten contenidos inapropiados. Si bien en 2010 las páginas que promovían el discurso del odio en forma de ataques a diferentes colectivos, y las que promovían desórdenes alimenticios eran las más populares, hoy acompañan en popularidad a las websites que incitan al odio aquellas que hablan de autolesionarse o lesionar a terceros. En general, hoy es más habitual acceder a este tipo de contenidos.

4 Por razones éticas, esta pregunta no se dirigió a los niños y las niñas de 9 y 10 años. 
La convergencia mediática, los riesgos y el daño online que encuentran los menores

Tabla 10. Menores (11-16 años) que han visto en páginas web contenidos potencialmente dañinos.

\begin{tabular}{|l|c|c|}
\hline \multicolumn{1}{|c|}{ \% sobre la base de todos los menores que usan internet } & $\mathbf{2 0 1 5}$ & $\mathbf{2 0 1 0}$ \\
\hline Lesionar a otros o autolesionarse & 17 & 8 \\
\hline Experiencias con drogas & 10 & 7 \\
\hline Mensajes de odio & 18 & 12 \\
\hline Desórdenes alimenticios & 14 & 11 \\
\hline Formas de suicidarse & 10 & 5 \\
\hline Algunas de ellas & 32 & 22 \\
\hline
\end{tabular}

Fuente: Elaboración propia. Base: Todos los menores de 11 a 16 años que usan internet.

\subsection{Otros riesgos}

Mientras la literatura sobre esta cuestión es aún dispersa, hay algunas evidencias de que el abuso y el mal uso de la información personal merecen atención. De acuerdo con los datos de EU Kids Online, el 9\% de los menores de 11 a 16 años han experimentado una o más de las tres formas de mal uso de la información personal que se investigaban, siendo las experiencias más habituales que alguien utilizara la contraseña de los niños o intentara hacerse pasar por ellos (ver tabla 11).

Los virus constituyen el riesgo con el que se encuentran más menores, uno de cada cuatro, que además se incrementa con la edad, pasando del $13 \%$ entre los niños más pequeños al $32 \%$ de los mayores. Por el contrario, que el teléfono se haya infectado por un virus ha sido reportado por una minoría de menores (5\%), siendo más habitual entre los más mayores, lógicamente.

Entre los riesgos asociados al mal uso de la información personal, es equivalente el porcentaje de menores que han experimentados riesgos relacionados con la privacidad habiendo detectado que alguien utilizó su información personal de una forma que no les gustó, o habiendo detectado que alguien usó su password o su teléfono para acceder a su información o suplantó su identidad. Aunque una minoría de menores están expuestos a este último riesgo (5\%), el porcentaje aumenta al 7\% para la franja de adolescentes de 15 y 16 años.

Haber perdido dinero real como resultado de un engaño en internet es menos común, sugiriendo quizá que los menores han aprendido cómo prevenir esas situaciones problemáticas, o bien que en sus rutinas de navegación no hay oportunidades para sufrir estas trampas. 
Tabla 11. Menores que han sufrido otras experiencias online negativas por edad.

\begin{tabular}{|c|c|c|c|c|c|}
\hline $\begin{array}{c}\text { Edad } \\
\text { \% sobre la base de todos los menores que usan internet }\end{array}$ & 9-10 años & 11-12 años & 13-14 años & 15-16 años & TOTAL \\
\hline $\begin{array}{l}\text { Alguien utilizó mi información personal de una manera de que } \\
\text { no me gustó }\end{array}$ & 2 & 3 & 8 & 4 & 5 \\
\hline El ordenador contrajo un virus & 13 & 20 & 29 & 32 & 23 \\
\hline El teléfono móvil/ smartphone contrajo un virus & 0 & 5 & 5 & 8 & 5 \\
\hline Perdí dinero (real) porque me engañaron en internet & 1 & 1 & 1 & 2 & 1 \\
\hline $\begin{array}{l}\text { Alguien uso mi contraseña/mi teléfono para acceder a mi } \\
\text { información o suplantó mi personalidad }\end{array}$ & 0 & 2 & 11 & 7 & 5 \\
\hline Alguna de ellas & 15 & 26 & 39 & 39 & 29 \\
\hline
\end{tabular}

Fuente: Elaboración propia. Base: Todos los menores que usan internet.

Si bien los datos señalados pueden considerarse satisfactorios por lo limitados, no deberíamos minimizar la relevancia de los riesgos asociados al mal uso de los datos personales; tal y como muestran las evidencias cualitativas en las que también hemos trabajado, los menores son particularmente sensibles a las cuestiones relacionadas con la privacidad (Garmendia et al. 2016).

\section{Conclusiones: Reaccionando a los riesgos}

La mayoría de las experiencias online no tienen por qué ser dañinas, y de hecho los menores no tienen por qué percibirlas como peligrosas o problemáticas (Livingstone et al., 2012; Vandoninck, d'Haenens \& Roe, 2013). Sin embargo, cuando se encuentran con experiencias negativas en internet, los menores despliegan una serie de estrategias para adaptarse a la situación y reducir el estrés emocional y psicológico derivado de la situación. Afrontar riesgos online implica, para los y las menores, adoptar "estrategias de resolución de problemas específicos de internet" tras una experiencia en línea negativa (Vandoninck et al., 2013, p. 61). La encuesta EU Kids Online (Livingstone et al., 2011) identificaba tres tipos de estrategias para afrontar los riesgos: respuestas pasivas, que incluyen actitudes resignadas (dejar de utilizar internet durante un tiempo) y autoacusatorias (sentirse culpable por lo que ha ocurrido); respuestas proactivas (como reportar o denunciar contenidos inadecuados o contactos inadecuados, bloquear a los contactos no deseados, etc.); y respuestas comunicativas (hablar sobre lo sucedido con los padres y madres, con pares, profesores u otros adultos de confianza). Aprender cómo gestionar las experiencias negativas de una manera eficaz, así como detectar cuáles son las respuestas más adecuadas y efectivas para cada ocasión, forma parte del proceso de construcción de resiliencia (Vandoninck et al., 2013; Vandoninck \& d'Haenens, 2018) y de adaptación al entorno.

La estrategia para afrontar los riesgos online más habitualmente adaptada por los menores pasa por buscar apoyo en su entorno social, aunque en la mayoría de los casos tienden a combinar dos estrategias (Livingstone et al., 2011). La investigación previa ha probado que los menores que reciben un apoyo mayor por parte de sus pares son más resistentes a las experiencias negativas en internet, y que tanto los padres como el profesorado están en la posición de mediar en la cons- 
trucción de resiliencia online si activamente se implican en las actividades online y de seguridad en internet de las que participan los niños (Vandoninck et al., 2013).

Madres (84\%), padres (76\%) y amigos (58\%) representan las fuentes de apoyo a las que recurrir de modo "muy" o "bastante" probable tras haber sufrido experiencias molestas en internet (ver tabla 12). Por el contrario, para la mayoría de los menores sería "muy" o "bastante" improbable recurrir a profesores (60\%) o personas dedicadas a ayudar a los niños que han sufrido experiencias online de carácter negativo (59\%).

Tabla 12. Con quién es probable que hablen los menores sobre cuestiones que les han molestado en internet.

\begin{tabular}{|c|c|c|c|c|c|}
\hline $\begin{array}{c}\text { \% sobre todos los menores que } \\
\text { usan internet }\end{array}$ & $\begin{array}{c}\text { Muy } \\
\text { probable }\end{array}$ & $\begin{array}{l}\text { Bastante } \\
\text { probable }\end{array}$ & $\begin{array}{c}\text { Bastante } \\
\text { improbable }\end{array}$ & Muy improbable & No procede \\
\hline Padre & 48 & 28 & 8 & 8 & 8 \\
\hline Madre & 61 & 23 & 6 & 5 & 6 \\
\hline Hermano o hermana & 19 & 15 & 14 & 24 & 28 \\
\hline Otros familiares & 13 & 20 & 20 & 31 & 16 \\
\hline Amigos/as & 28 & 30 & 14 & 18 & 10 \\
\hline Profesores/as & 4 & 14 & 19 & 41 & 21 \\
\hline $\begin{array}{l}\text { Alguien que se dedica a ayudar } \\
\text { a los menores }\end{array}$ & 8 & 11 & 16 & 44 & 20 \\
\hline Un adulto en el que confío & 12 & 20 & 18 & 34 & 16 \\
\hline
\end{tabular}

Fuente: Elaboración propia. Base: Todos los menores que usan internet.

Para las niñas y los niños más pequeños es más probable hablar con su padre o su madre que con cualquier otro interlocutor, destacando que tanto para niños como para niñas la probabilidad de hablar con la madre es mayor. La importancia de padres y madres como fuente primaria de apoyo en caso de experiencias desagradables disminuye con la edad, y particularmente entre los niños. Paralelamente, los adolescentes son más propensos que los niños más pequeños a recurrir a sus pares para buscar apoyo. El género marca variaciones de importancia: las chicas adolescentes tienden a hablar con sus amigos, y más aún con sus madres y, en general, las chicas consideran con más probabilidad hablar con todos los interlocutores sugeridos salvo con el padre. Si bien en general los menores no consideran hablar con sus profesores, los chicos y las chicas más jóvenes se inclinan a señalarlos como fuente de apoyo en mayor medida que los adolescentes, que apenas los consideran como posibles interlocutores. La probabilidad de hablar con personas dedicadas a ayudar a los menores, hermanos y hermanas u otros familiares o adultos en los que se confía también disminuye, aunque a ritmos diferentes, según aumenta la edad de los menores.

Es probable que el $82 \%$ de los menores hable al menos con una persona tras haber sufrido una experiencia online negativa. Apenas hay diferencias sustanciales por edad y género: la proporción de menores dispuestos a hablar con al menos una 
persona sobre lo que les molesta en internet es algo superior en el caso de los menores más jóvenes (84\%) y de las niñas (83\%) que en el de los mayores (80\%) y los niños (82\%), pero las cifras son equivalentes. Sin embargo, las variaciones en función del nivel de estudios de los progenitores son, comparativamente, las más destacables. Los menores provenientes de familias con menor nivel de estudios (y probablemente con menos habilidades digitales) están menos predispuestos a recurrir a alguien para compartir una experiencia online desagradable.

Estos resultados sugieren que los menores valoran particularmente el papel de padres, madres y el de sus iguales, con lo cual estos agentes deberían ser muy considerados en las iniciativas de regulación. Por otra parte, aún hay un 18\% de menores que afirma que no recurriría a nadie en caso de encontrarse con experiencias desagradables en internet. Al diseñar políticas de acción al respecto las autoridades deberían asegurar que todos los niños y las niñas encuentren el apoyo social necesario, del tipo que sea.

No obstante, existe una creciente concienciación sobre los riesgos online entre padres y madres y menores que se manifiesta en una mayor participación de los progenitores en la mediación de la seguridad de los menores online, y en el desarrollo de habilidades de seguridad o la adopción de medidas preventivas entre los menores.

La exposición a los riesgos online se ha incrementado en los últimos años, especialmente entre los menores que utilizan móviles y tabletas para navegar. La máxima de "más oportunidades, más riesgos" constituye un marco válido para entender los cambios relacionados con los smartphones y las tabletas, cambios que conducen a un internet más ubicuo y omnipresente en el día a día de los menores.

Dado que aumenta el porcentaje de niños internautas, desde más temprana edad, y que lo son desde más aparatos y en contextos más variados, no resulta sorprendente que la exposición a riesgos online también aumente. Es necesario resaltar que el incremento de aquellos que han sufrido daños como resultado de experiencias de riesgo no ha aumentado en la misma proporción.

El acoso continúa siendo el riesgo que más daño causa a quienes lo sufren, pero pese a un cierto discurso social y mediático y a las posibilidades que las redes sociales dan para amplificar situaciones de abuso, aún son muchos más los casos de ciberbullying que son una prolongación del cara a cara que los que, en palabras de los afectados, tienen lugar en el espacio online.

La mediación de la familia es fundamental para prevenir y gestionar los riesgos en internet y los usos inadecuados. En casi todos los grupos observados se detectan carencias en esa área, y en muchas ocasiones se debe a la baja alfabetización digital de sus progenitores. Las herramientas digitales para la socialización pueden ser de utilidad para facilitar su integración: redes como WhatsApp (y otras) les permite socializar con sus compañeros de clase al margen de la escuela.

En cualquier caso, y a pesar de que los menores son más conscientes de los peligros asociados al ciberacoso u otras situaciones potencialmente conflictivas, sigue siendo necesario promover usos de la comunicación móvil más seguros y responsables. Esto podría pasar por incrementar la conciencia sobre las cuestiones relacionadas con la privacidad, las aplicaciones diseñadas para denunciar o bloquear, las funciones vinculadas al control y la geolocalización o los riesgos asociados a la escalada de intercambios que a veces se dan en casos de conflictos online (Marwick \& Boyd, 2014). 


\section{Referencias bibliográficas}

Attwood, F. \& Smith, C. (2011). Investigating young people’s sexual cultures: an introduction. Sex Education, 11(3), pp. 235242. DOI: $10.1080 / 14681811.2011 .590040$

Barbouschi, M. Marinescu, V. Velicu, Anca \& Laszlo, E. (2012). Meeting new contacts online. In Livingstone, S. Haddon, L. \& Görzig, A. (Ed.), Children, risk and safety on the internet: Research and policy challenges in comparative perspective. (pp. 177-189). Bristol: Policy Press.

Boyd, D. (2008) Why youth (heart) social network sites: the role of networked publics in teenage social life. In D. Buckingham (ed.) Youth, identity and digital media (pp. 119-142). Cambridge, MA: MIT Press.

Buckinggham, D. \& Bragg, S. (2004). Young people, sex and the media, Basingstoke. Palgrave Macmillan.

Ey, L. A. \& Cupit, C. G. (2011). Exploring young children's understanding of risk associated with Internet usage and their concepts of management strategies. Journal of Early Chilhood Research 23. https://doi.org/10.1177/1476718X10367471.

Garmendia, M. Jiménez, E., Casado, M.A. y Mascheroni, G. (2016). Net Children Go Mobile: Riesgos y oportunidades en internet y el uso de dispositivos móviles entre menores españoles (2010-2015). Madrid: Red.es/Universidad del País Vasco/ Euskal Herriko Unibertsitatea.

Goggin, G. (2010). Global mobile media. New York: Routledge.

Goggin, G., Hjorth, L. (2014). The Routledge Companion to Mobile Media. New York: Routledge.

Hjorth, L. \& Goggin, G. (2009). Mobile technologies: From telecommunications to media. London: Routledge.

Ito, M., Baumer, S., Bittanti, M., Boyd, D., Cody, R., Herr-Stephenson, B., Tripp, L. (2009) Hanging out, messing around and geeking out: Kids living and learning with new media. Cambridge, MA: MIT Press.

Kernaghan, D. \& Elwood, J. (2013). All the (cyber) world's a stage: Framing cyberbullying as a performance. Cyberpsychology: Journal of Psychosocial Research on Cyberspace, 7(1), http://dx.doi.org/10.5817/CP2013-1-5

Kofoed, J. \& Ringrose, J. (2012). Travelling and sticky affects: Exploring teens and sexualized cyberbullying through a Butlerian-Deleuzian-Guattarian lens. Discourse: Studies in the Cultural Politics of Education, 33(1), 5-20.

Lampert, C. \& Donoso, V. (2012). Bullying. In Livingstone, S. Haddon, L. \& Görzig, A. (Ed.), Children, risk and safety on the internet: Research and policy challenges in comparative perspective. (pp. 165-176). Bristol: Policy Press.

Lenhart, A. (2009). Teens and sexting: How and why minor teens are sending sexually suggestive nude or nearly nude images via text messaging. Washington, DC: Pew Research Center. Disponible en: http://pewresearch.org/assets/pdf/teens-andsexting.pdf.

Levy, N., Cortesi, S., Crowley, E., Beaton, M., Casey, J. \& Nolan, C. (2012). Bullying in a networked era: A literature review. Berkman Center Research Publication, 17. Disponible en: http://cyber.law.harvard.edu/publications/2012/ $k b w \_b u l l i n g \_i n \_a \_n e t w o r k e d \_e r a$. 
Livingstone, S., Hasebrink, U. \& Görzig, A. (2012). Towards a general model of determinants of risks and safety. In S. Livingstone, L. Haddon, \& A. Görzig (eds.) Children, risk and safety on the internet (pp. 323-339). Bristol: Policy Press.

Livingstone, S., Haddon, L., Görzig, A., \& Ólafsson, K. (2011). Risks and safety on the internet: The perspective of European children. Full findings. London: LSE, EU Kids Online.

Marwick, A., \& Boyd, D. (2014). "It's just drama”: teen perspectives on conflict and aggression in a networked era. Journal of Youth Studies.

Ólafsson, K., Livingstone, S. \& Haddon, L. (2013). Children's use of online technologies in Europe: a review of the European evidence base. EU Kids Online, London, UK.

Ringrose, J., Gill, R., Livingstone, S., \& Harvey, L. (2012). A qualitative study of children, young people and 'sexting': A report prepared for the NSPCC. London: National Society for the Prevention of Cruelty to Children.

Rovolis, A. \& Tsaliki, L. (2012). Harm, childhood and appropriate media content: an ongoing debate. In Livingstone, S. Haddon, L. \& Görzig, A. (Ed.), Children, risk and safety on the internet: Research and policy challenges in comparative perspective. (pp. 165-176). Disponible en: https://books.google.es/books?hl=es\&lr=\&id=R_hfWbE3DwC\&oi=fnd\&pg=PA165\&dq=Rovolis+\%26+Tsaliki,+2012\&ots=xiCXXG_FuA\&sig=VbOEgc9nF6GblTiT19TPwF_4-vs\#v=onepage\&q=Rovolis\%20\%26\%20 Tsaliki\%2C\%202012\&f=false

Schrock, A. \& Boyd, D. (2008). Online threats to youth: Solicitation, harassment, and problematic content: Literature review prepared for the Internet Safety Technical Task Force. Disponible en: http://cyber.law.harvard.edu/sites/cyber.law.harvard. edu/files/RAB_Lit_Review_121808_0.pdf

Vandoninck, S., d'Haenens, L., \& Roe, K. (2013). Online risks: Coping strategies of less resilient children and teenagers across Europe. Journal of Children and Media, 7(1), 60-78.

Vandoninck, S.\& d'Haenens, L. Resilience online: la capacidad para minimizar el impacto de los riesgos y gestionar las situacione potencialmete dañinas. In Jiménez, E. Garmendia, M. \& Casado M.A., (Ed.), Entre selfies y whatsapps: Oportunidades y riesgos para la infancia conectada. (pp. 189-206). Barcelona: Gedisa.

Ybarra, M. L. \& Mitchel, J. M. (2014). "Sexting” and Its Relation to Sexual Activity and Sexual Risk Behavior in a National Survey of Adolescents. Journal of Adolescent Health, 55, 757-764.

Zych, I.; Ortega-Ruiz, R. y del Rey, R. (2015). Systematic review of theoretical studies on bullying and cyberbullying. facts, knowledge, prevention, and intervention. Aggression and Violent Behaviour, 23, pp. 1-21. DOI 10.1016/j.avb.2015.10.001 
